\title{
Determination of Resistance Levels of Some Onion Cultivars or Inbreed Lines with Fusarium Testing at Seedling Stage
}

\author{
Ebrar KARABULUT ${ }^{1}$ (i) Ali Fuat GÖKÇE²
}

${ }^{1}$ Niğde Ömer Halisdemir University, Graduate School of Natural and Applied Sciences, Department of Agricultural Genetic Engineering, 51420, Niğde, Turkey

2 Niğde Ömer Halisdemir University, Faculty of Agricultural Sciences and Technologies, Department of Agricultural Genetic Engineering, 51420, Niğde, Turkey

\section{Article History}

Received 26 May 2021

Accepted 30 January 2022

First Online 10 February 2022

Corresponding Author

E-mail: ebrarkarabulut95@gmail.com

\section{Keywords \\ Damping off \\ Fusarium \\ Onion \\ Seedling testing}

\begin{abstract}
This study was carried out to determine the resistance levels of some onion genotypes in Yalova onion gene pool by Fusarium testing during seedling stage. The isolate used in the study was Fusarium oxysporum f. sp. cepae, which causes damping off during the seedling stage and later basal rot in onion bulbs. The variance analysis for the onion seedling test and the mean differences against control were analyzed by using General Linear Model of the Tukey test. The germination rate of control seeds varied between $72 \%$ to $98 \%$, while the germination rate of inoculated seeds varied between $39 \%$ to $93 \%$. Texas Early Grano 502 showed the highest level of resistance with a survival rate of $83.8 \%$, and resistance levels of 19 Y07 and $19 Y 142$ genotypes were higher than other genotypes. Resistance levels of 19Y51, 19Y15 and $19 Y 73$ genotypes were lower than other genotypes. Akgün 12 showed moderate resistance with a survival rate of $59.6 \%$. Determining the resistance levels of these onion genotypes during the seedling stage may be a preliminary step towards further studies.
\end{abstract}

\section{Introduction}

Onion (Allium cepa L.), belonging to the Alliaceae family is a significant vegetable crop worldwide. Onion is the herbaceous biennial crop, and it has a wide range of landraces and cultivars with edible bulbs (Nasr Esfahani, 2018; Singh et al., 2018). The onion plant can be infected by soil- and seed-borne fungal pathogens, resulting in significant yield and quality losses.

Fusarium oxysporum Schlechtend.: Fr. f. sp. cepae (Hans) Synder and Hans (FOC) is caused seedborne and soilborne diseases such as damping off and basal root (Köycü and Özer, 1997; Özer et al., 2003). This pathogen may be seen and noticed in different growth stages of onion and can cause serious loss in the field and during storage (Fantino and Schiavi, 1987; Özer et al., 2003). Symptoms of Fusarium basal rot (FBR) appear on leaves, roots, basal plates, on the bulb scales of small seedlings, on the mature and dormant plants (Cramer, 2000; Özer et al., 2003). Symptoms are pre- and post-emergence damping-off of seedling in the field, root rot in older plants, discoloration in onion stem plate, basal rot in bulbs during storage (Abawi and Lorbeer, 1972; Cramer, 2000).

Fusarium oxysporum f. sp. cepae (FOC) exist in many countries such as the United States, Brazil, South Africa, the Netherlands, India, England, Iran, Sweden, Japan, and Uruguay, where onions are grown around the world (Cramer, 2000; Galvan et al., 2008; Dissanayake et al., 2009; Lager, 2011; Ghanbarzadeh et al., 2014; Ünsal et al., 2019) and also FOC exist in Turkey in onion production areas (Türkkan and Karaca, 2006; Bayraktar and Dolar, 2011).

Fusarium oxysporum f. sp. cepae can lead to losses reaching up to $50 \%$ in the field and $75 \%$ in 
the greenhouse (Brayford, 1996; Stadnik and Dhingra, 1997; Ünsal et al., 2019). For this reason, the development and application of the most effective control methods of this destructive pathogen are vital. This pathogen can be controlled with some control methods such as resistance of host plant, crop rotation, solarization, various biological applications, and fungicide applications (Cramer, 2000; Ünsal et al., 2019). However, the using of resistant varieties is economic, applicable on a large scale, and stated as the best option (Cramer, 2000; Nasr Esfahani et al., 2012; Özer et al., 2003; Özer et al., 2004).

Many management strategies have been developed in the world for the detection and control of FOC. But over the time, control methods have become limited and inadequate. Therefore, it has become very important to identify and develop varieties that are tolerant or resistant to this pathogen. Resistance studies against FOC in onion have been performed before (Özer et al., 2003; Özer et al., 2004; Saxena and Cramer, 2009; Nasr Esfahani et al., 2012; Taylor et al., 2013). However, in this study, no previous study was conducted to define the resistance levels of 13 onion genotypes that were taken from the Yalova gene pool with Akgün 12 and grown in the same environment.

The goal of this study is to determine onion genotypes tolerance levels to develop tolerant varieties for commercial production. Developing resistance cultivars will prevent the loss of crops in the field and storehouse and will contribute to the national economy. This study aims to determine the tolerance/resistance level of some onion genotypes at the seedling stage. In this study, resistance levels of some onion genotypes to this pathogen were determined.

\section{Materials and Methods}

The plant materials were formed from 13 onion genotypes and 2 onion varieties. The onion genotypes were labeled 19Y01, 19Y06, 19Y07, 19Y15, 19Y16, 19Y17, 19Y18, 19Y19, 19Y34, 19Y46, 19Y51, $19 Y 73$ and 19Y142. Akgün 12 and Texas Early Grano 502 have used as onion varieties. The thirteen genotypes and Akgün 12 were provided from Yalova onion gene pool and Texas Early Grano (TEG) 502 was provided by Bayram Seed Company. Whereas Akgün 12 onion variety was used as tolerant, TEG 502 variety was used as susceptible against $F$. oxysporum $\mathrm{f}$. sp. cepae as reported according to previous research (Ko et al., 2002; Özer et al., 2003). The susceptibility levels of other onion genotypes were not known. As fungal material, one pathogenic and virulence isolate to be used in this study was provided from Ankara University, Agriculture Faculty, Plant Protection Department.

Onion seedling test was carried out by the method of inoculation of onion seeds. Onion seedling test was mainly included sterilization of onion seeds, preparation of spore suspension, inoculation of onion seeds, sowing of onion seeds in the soil, and counting of seeds and seedlings. Initially, surface sterilization of onion seeds from each genotype was performed in the flow cabinet in the Mycology Laboratory, Plant Protection Department, Atatürk Horticultural Crops Central Research Institute. The onion seeds were kept in $1000 \mu \mathrm{l} 1 \%$ sodium hypochlorite for 3 minutes in the Eppendorf tubes to disinfect the surface, then seeds were rinsed in the sterile distilled water 3 times and left to get dry on sterile filter papers. Then Fusarium oxysporum f. sp. cepae was cultured on PDA medium at $20^{\circ} \mathrm{C}$ for 10 days. Sterile water was added into the petri dish to allow the conidia to pass into the water onto the developing culture and filtered through the sterile cheesecloth by gentle mixing and the intensity of the spore was adjusted to a density of $1 \times 10^{6} \mathrm{ml}^{-1}$ by the hemocytometer.

After preparation of spore suspension, each onion genotype was inoculated by standing in $1 \mathrm{ml}$ of spore suspension for 1 hour and the seeds used for control were kept in $1 \mathrm{ml}$ sterile purified water for 1 hour. After 1 hour, seeds were rinsed and put back into petri dishes.

Before sowing the seeds, the $1 / 3$ garden soil + $1 / 3$ farm manure $+1 / 3$ stream sand mixture was filled in the fireproof bag and placed in the autoclave machine (60 $\left.\mathrm{min}, 121^{\circ} \mathrm{C}\right)$ to be a sterile soil mixture. For each treatment, 100 seeds were planted for each genotype with independent 4 replications in each replication with 25 seeds.

The seeds planted in the seedling trays $(10 \times 12$ cells per tray) were placed in the climate chamber and the climate chamber was adjusted to be $25^{\circ} \mathrm{C}$ day $/ 18^{\circ} \mathrm{C}$ night and 16-hour light / 8-hour dark and $60 \%$ relative humidity. The counting of survival seedlings was performed twice a week after 10 days of planting and continued for 3 weeks (Özer et al., 2004; Taylor et al., 2013). The survival percentage of the genotypes was calculated according to control genotypes to ensure a variation of natural in the seed germination.

The data obtained before and after the seedling emergence were compared with the control. The variance analysis for the onion seedling test was analyzed by using the General Linear Model of the Tukey test. Variance analyses were performed with Minitab ${ }^{\circledR}$ 16.2.4 (e-academy version). Paired Sample T-Test for comparison of control and inoculated alive seedlings were analyzed by using Microsoft Excel. Counting of dead and alive seeds and seedlings were taken after two weeks and four weeks and the percentage of emergence and survival were calculated with the formula below (Saxena and Cramer, 2009).

$$
\begin{aligned}
& \% \text { Emergency }=\frac{\text { Emerged seedlings }}{\text { Total planted seed }} \times 100 \\
& \% \text { Survival }=\frac{\text { Survival seedlings }}{\text { Total emerged seedling }} \times 100
\end{aligned}
$$




\section{Results and Discussion}

\subsection{Observation of disease symptoms}

FOC caused germination, plant death and adverse effects on the length and weight of the root and stem in plant disease studies (Behrani et al., 2015). On that account, significant differences were noted between plant growths of inoculated and control plants (Figure 1). Ten days after inoculation, germination almost completed for inoculated and control seeds.

Twelve days after inoculation, the initial disease symptoms began to seem such as the appearance of white mycelium on the soil and the death of several small seedlings (Figure 2). Before germination, it either germinated later than controls or death occurred. After germination, inoculated seedlings developed later than control. Yellowing occurred on the onion leaves (Figure 3). Cramer (2000) noticed that white mycelium may be on the basal plate of external bulb scales. Like to this work, white mycelium was noticed on the soil of the onion seedling during seedling stage in this study (Figure 2 ). It was noteworthy that when the root part of the seedlings that looked healthy in the soil was removed from the soil, it was already brown and broken. If the study had continued, seedlings would continue to die (Figure 4).

\subsection{Onion seedling test}

A total of 13 onion genotypes and 2 onion varieties inoculated by the seed inoculation method were evaluated about resistance against FOC. There were highly significant differences among onion genotypes due to infection caused by FOC.

In this study, the percentage of germinated seeds, the percentage of alive seedlings and the percentage of dead seedlings in the inoculated onion seeds were calculated by comparing them with the control seedlings. At the end of the 4-week counts, the obtained data were evaluated, analyzed and the resistance levels against damping-off were determined among the onion genotypes (Table 1).

Dead seeds shown in the control seeds were non-germinated seeds. These dead seeds were percentage of seeds that were not germinated by their nature. In the case of inoculated seeds, it was showed the percentage of seedlings that died after germination. It was observed that germinated seeds and alive seedlings of onion genotypes had similar values, while their dead seedlings had significant differences. While the mean percentage of germinated seeds was found to be 70.26 , the mean percentage of alive seedlings was found to be 57.00. The mean percentage of dead seedlings was found to be 21.40. In addition, when looking at dead seedlings, significant differences were observed

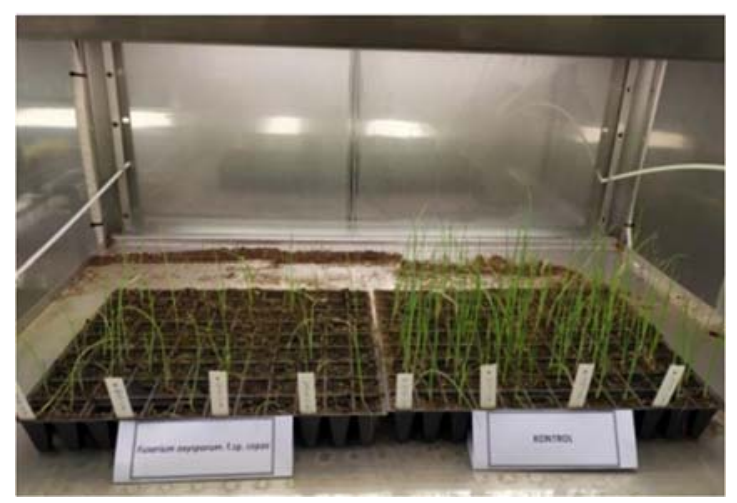

Figure 1. Final comparison between inoculated and control seedlings
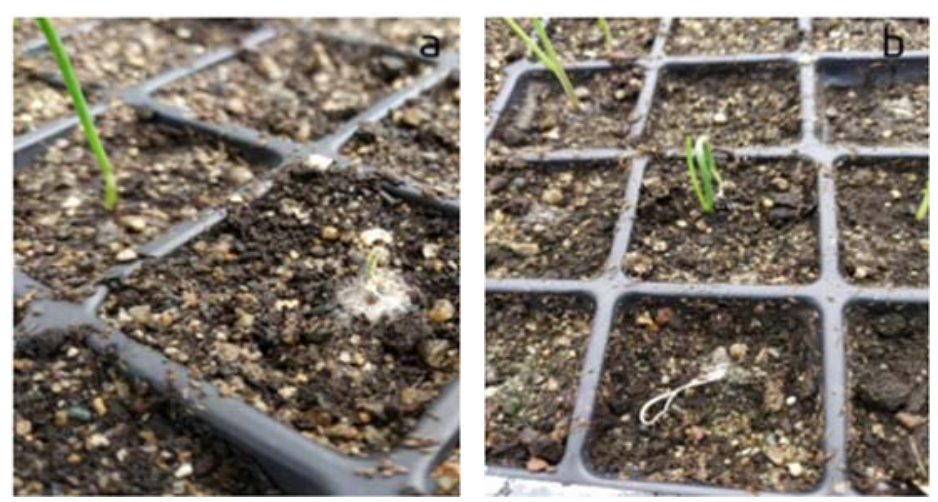

Figure 2. View of dead seed and seedling and the formation of white mycelium $(a, b)$
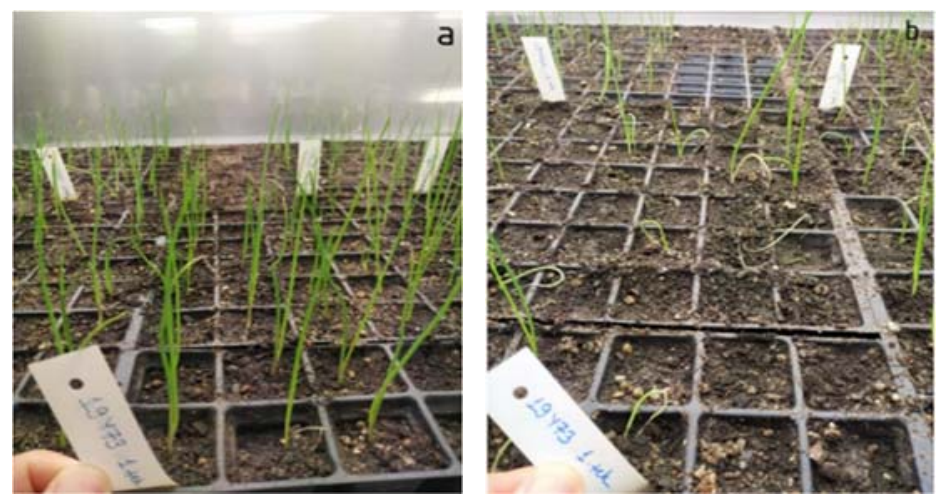

Figure 3. Comparison of control (a) and inoculated seedlings (b) of $19 Y 73$

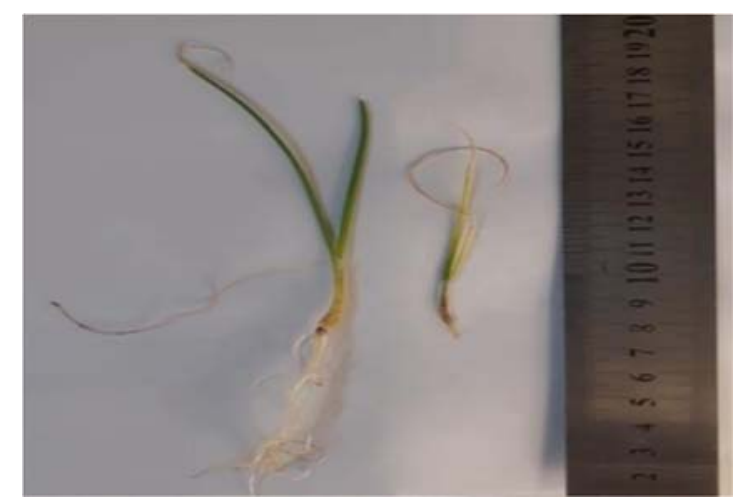

Figure 4. Comparing of the alive and dead seedling in the same inoculated genotype 
between genotypes both according to control genotypes and among themselves (Table 1).

The mean of control dead seedlings was unexpectedly higher than inoculated dead seedlings in some genotypes (Table 1). These genotypes can be listed as follows: 19Y51, 19Y15, Akgün 12, 19Y46, 19Y34, 19Y01, and 19Y07. In the $19 Y 16$ genotype, the mean of control and inoculated dead seedlings were equal. Other onion genotypes had higher average dead seedlings in inoculated genotypes as expected in the Table 1. Another remarkable point was that TEG 502 onion variety has more average germinated seeds than other genotypes in both control and inoculated seeds in the Table 1 . Then the mean of control and inoculated alive seedlings at the end of the experiment were given comparatively in the Table 2.

Significant difference was not observed between control and inoculated live seedlings of some genotypes. Examples of these genotypes were 19Y06, 19Y19, 19Y142, Akgün 12 and TEG $502(P$ $>0.05)$. Significant differences $(P<0.05)$ were seen in other onion genotypes (Table 2 ). When mean of the control and inoculated alive seedlings were compared, there were no statistically significant differences for some onion genotypes such as TEG 502 ( $P=0.253)$, Akgün $12(P=0.110), 19 Y 142(P$ $=0.223), 19 Y 19(P=0.063)$ and 19 Y06 $(P=0.427)$.

Two onion varieties and 13 onion genotypes were inoculated by a FOC isolate. Then, seedling emergence rate and survival rate of onion seedlings at $2^{\text {nd }}$ and $4^{\text {th }}$ week were calculated and compared with each other in the Table 3 . This evaluation was done with using the formula given by Saxena and Cramer (2009).

The survival seedling rates among onion genotypes ranged from $89.7 \%$ to $100 \%$ in the $2^{\text {nd }}$ week, while survival seedling rates ranged from $39.02 \%$ to $83.87 \%$ in the $4^{\text {th }}$ week (Table 3 ). If the study had continued, it would have estimated that the survival seedling rates, would continue to decrease in the following weeks.

Each onion genotype did not differ significantly at $2^{\text {nd }}$ and $4^{\text {th }}$ weeks. For example, FOC isolate caused a little change of pre- and post-emergence damping-off, by a decrease from $100 \%$ survival rate after 2 weeks to $83.87 \%$ survival rate after 4 weeks in TEG 502. However, FOC isolate caused a significant amount effect of pre- and postemergence damping off, with a decrease from $90.24 \%$ survival rate after 2 weeks to $39.02 \%$

Table 1. Genotypes, experiment, mean percentages of the germinated seeds, alive and dead seedlings of control and inoculated seeds.

\begin{tabular}{|c|c|c|c|c|c|c|c|c|}
\hline \multirow{2}{*}{ Genotypes } & \multirow{2}{*}{ Experiment } & \multirow{2}{*}{$\mathrm{N}$} & \multicolumn{2}{|c|}{ Germinated seeds } & \multicolumn{2}{|c|}{ Alive seedlings } & \multicolumn{2}{|c|}{ Dead seedlings } \\
\hline & & & Mean & $G$ & Mean & $G$ & Mean & G \\
\hline TEG 502 & Control & 4 & 98.00 & $a^{*}$ & 98.00 & $a$ & 2.00 & $\mathrm{C}$ \\
\hline TEG 502 & FOC & 4 & 93.00 & $a b$ & 78.00 & a & 15.00 & ac \\
\hline 19Y18 & Control & 4 & 88.00 & $\mathrm{ac}$ & 88.00 & a & 12.00 & bc \\
\hline $19 Y 18$ & FOC & 4 & 64.00 & bh & 38.00 & $\mathrm{~cd}$ & 26.00 & $a b$ \\
\hline 19Y142 & Control & 4 & 85.00 & $\mathrm{ad}$ & 85.00 & a & 15.00 & ac \\
\hline 19Y142 & FOC & 4 & 71.00 & ag & 50.00 & bc & 21.00 & ac \\
\hline 19Y17 & Control & 4 & 84.00 & ad & 84.00 & a & 16.00 & ac \\
\hline $19 Y 17$ & FOC & 4 & 62.00 & $\mathrm{ch}$ & 37.00 & $\mathrm{~cd}$ & 25.00 & ac \\
\hline $19 Y 19$ & Control & 4 & 83.00 & ae & 83.00 & $a$ & 17.00 & ac \\
\hline $19 Y 19$ & FOC & 4 & 60.00 & $\mathrm{ch}$ & 31.00 & $\mathrm{~cd}$ & 29.00 & $a b$ \\
\hline $19 Y 16$ & Control & 4 & 80.00 & $\mathrm{ae}$ & 80.00 & $a$ & 20.00 & ac \\
\hline $19 Y 16$ & FOC & 4 & 60.00 & $\mathrm{ch}$ & 40.00 & $\mathrm{~cd}$ & 20.00 & $\mathrm{ac}$ \\
\hline $19 Y 07$ & Control & 4 & 79.00 & $\mathrm{ae}$ & 79.00 & $a$ & 21.00 & ac \\
\hline $19 Y 07$ & FOC & 4 & 43.00 & gh & 32.00 & $\mathrm{~cd}$ & 11.00 & $\mathrm{~b}$ \\
\hline 19Y06 & Control & 4 & 79.00 & ae & 79.00 & $a$ & 21.00 & ac \\
\hline 19Y06 & FOC & 4 & 72.00 & ag & 36.00 & $\mathrm{~cd}$ & 36.00 & a \\
\hline 19Y01 & Control & 4 & 77.00 & $\mathrm{ae}$ & 77.00 & $a$ & 23.00 & ac \\
\hline $19 Y 01$ & FOC & 4 & 44.00 & $\mathrm{gh}$ & 28.00 & $c d$ & 16.00 & ac \\
\hline $19 Y 73$ & Control & 4 & 77.00 & ae & 77.00 & $a$ & 23.00 & $\mathrm{ac}$ \\
\hline $19 Y 73$ & FOC & 4 & 45.00 & fh & 21.00 & d & 24.00 & ac \\
\hline $19 Y 34$ & Control & 4 & 74.00 & af & 74.00 & $a b$ & 26.00 & $a b$ \\
\hline $19 Y 34$ & FOC & 4 & 54.00 & eh & 30.00 & $\mathrm{~cd}$ & 24.00 & ac \\
\hline $19 Y 46$ & Control & 4 & 74.00 & af & 74.00 & $a b$ & 26.00 & $a b$ \\
\hline $19 Y 46$ & FOC & 4 & 47.00 & $\mathrm{fh}$ & 26.00 & $\mathrm{~cd}$ & 21.00 & ac \\
\hline Akgün 12 & Control & 4 & 74.00 & af & 74.00 & $a b$ & 26.00 & $a b$ \\
\hline Akgün 12 & FOC & 4 & 57.00 & $\mathrm{dh}$ & 34.00 & $\mathrm{~cd}$ & 23.00 & $\mathrm{ac}$ \\
\hline $19 Y 15$ & Control & 4 & 72.00 & ag & 72.00 & $a b$ & 28.00 & $a b$ \\
\hline $19 Y 15$ & FOC & 4 & 39.00 & $\mathrm{~h}$ & 17.00 & $d$ & 22.00 & ac \\
\hline $19 Y 51$ & Control & 4 & 72.00 & ag & 72.00 & $a b$ & 28.00 & $a b$ \\
\hline $19 Y 51$ & FOC & 4 & 41.00 & $\mathrm{~h}$ & 16.00 & d & 25.00 & $\mathrm{ac}$ \\
\hline General Me & & & 70.26 & & 57.00 & & 21.40 & \\
\hline General SE & & & 5.45 & & 4.89 & & 4.26 & \\
\hline
\end{tabular}

*Different letters following the mean in the same column signify that the mean is statistically significant difference.

(ANOVA $p=0.05$, Tukey test). N: Number of replication. G: Grouping. 
Table 2. Genotypes, comparison of control and inoculated alive seedlings.

\begin{tabular}{|c|c|c|c|c|c|}
\hline \multirow{2}{*}{ Genotypes } & \multicolumn{2}{|c|}{ Control alive seedling } & \multicolumn{2}{|c|}{ Inoculated alive seedling } & \multirow{2}{*}{$p$-value* } \\
\hline & Mean & Std Dev & Mean & Std Dev & \\
\hline $19 Y 01$ & 0.77 & 0.09 & 0.44 & 0.12 & 0.005 \\
\hline $19 Y 06$ & 0.79 & 0.14 & 0.72 & 0.09 & 0.427 \\
\hline 19Y07 & 0.79 & 0.02 & 0.43 & 0.23 & 0.021 \\
\hline $19 Y 15$ & 0.72 & 0.03 & 0.39 & 0.07 & 0.000 \\
\hline 19Y16 & 0.80 & 0.09 & 0.60 & 0.05 & 0.012 \\
\hline $19 Y 17$ & 0.84 & 0.09 & 0.62 & 0.10 & 0.016 \\
\hline $19 Y 18$ & 0.88 & 0.09 & 0.64 & 0.09 & 0.008 \\
\hline $19 Y 19$ & 0.83 & 0.11 & 0.60 & 0.16 & 0.063 \\
\hline $19 Y 34$ & 0.74 & 0.11 & 0.54 & 0.07 & 0.043 \\
\hline $19 Y 46$ & 0.74 & 0.07 & 0.47 & 0.07 & 0.002 \\
\hline $19 Y 51$ & 0.72 & 0.09 & 0.41 & 0.13 & 0.009 \\
\hline $19 Y 73$ & 0.77 & 0.04 & 0.45 & 0.12 & 0.003 \\
\hline 19Y142 & 0.85 & 0.10 & 0.71 & 0.10 & 0.223 \\
\hline TEG 502 & 0.98 & 0.04 & 0.93 & 0.04 & 0.253 \\
\hline Akgün 12 & 0.74 & 0.16 & 0.57 & 0.04 & 0.110 \\
\hline
\end{tabular}

*(Paired Sample T-Test, $p=0.05)$.

Table 3. Genotypes, percentages of emergence and survival rate of onion seedlings.

\begin{tabular}{lccc}
\hline \multirow{2}{*}{ Genotypes } & \multicolumn{3}{c}{ Inoculated seeds } \\
\cline { 2 - 4 } & \% Emergence & \% Survival $\left(2^{\text {nd }}\right.$ week $)$ & \% Survival $\left(4^{\text {th }}\right.$ week $)$ \\
\hline 19Y51 & 41.00 & 90.24 & 39.02 \\
$19 Y 15$ & 39.00 & 89.70 & 43.58 \\
19Y73 & 45.00 & 93.33 & 46.66 \\
$19 Y 06$ & 72.00 & 93.05 & 50.00 \\
19Y19 & 60.00 & 90.00 & 51.66 \\
19Y46 & 47.00 & 97.87 & 55.31 \\
19Y34 & 54.00 & 96.29 & 55.55 \\
19Y18 & 64.00 & 93.75 & 59.37 \\
Akgün 12 & 57.00 & 91.22 & 59.64 \\
19Y17 & 62.00 & 90.32 & 59.67 \\
19Y01 & 44.00 & 95.45 & 63.63 \\
19Y16 & 60.00 & 98.33 & 66.66 \\
19Y142 & 71.00 & 98.59 & 70.42 \\
19Y07 & 43.00 & 97.67 & 74.41 \\
TEG 502 & 93.00 & 100.00 & 83.87 \\
\hline Mean & 56.80 & 94.38 & 58.63 \\
\hline
\end{tabular}

${ }^{*}$ Emergence rate and survival rate of onion seedlings at $2^{\text {nd }}$ and $4^{\text {th }}$ week was calculated using the formula given by Saxena and Cramer (2009).

survival rate after 4 weeks in 19Y51. As another example, although 19 Y07 onion genotype has more loss than 19Y142 in terms of damping off before germination, 19Y07 onion genotype has less loss in terms of damping-off after germination than 19Y142 (Table 3). Moreover, among genotypes, while the survival rate of genotypes $19 Y 15$ and 19Y51, where the first symptoms were seen, was the lowest compared to others, TEG 502 onion variety showing the last symptom had the highest survival rate (Table 3).

Özer et al. (2003) measured disease severity of onion varieties 7 days after inoculation and they observed that the disease severity of TEG 502 was higher than the disease severity of Akgün 12. Ko et al. (2002) remarked that TEG 502 was the most susceptible to FOC. For another study, Galvan et al. (2008) noted that the TEG 502 onion variety was less resistant in their study. Nasr-Esfahani et al. (2013) announced that TEG was one of the susceptible onion genotypes in field and greenhouse conditions. In contrast, according to the data obtained in this study, at the end of the 4th week, in the inoculated seeds, TEG 502 showed $83.87 \%$ survival rate and $93.0 \%$ emergence rate in the Table 3. Thus, unlike other studies, it was observed that the resistance level of TEG 502 was highest against damping-off before and after germination (Figure 5).

According to a study by Özer et al. (2004), while Akgün 12 variety was found to be resistant in all bulb stages in their all experiments, in this study, the survival rate of Akgün 12 was showed $59.64 \%$ (Table 3). In this case, it was observed that Akgün 12 showed a moderate level of resistance against damping-off during the seedling stage. Akgün 12 

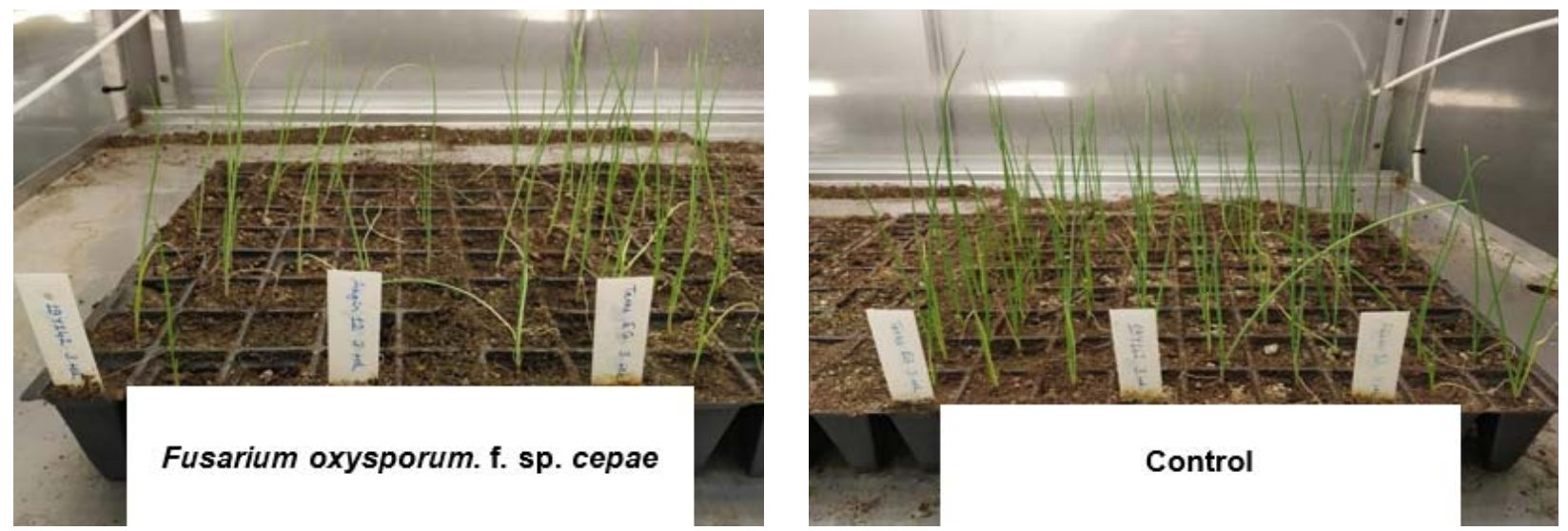

Figure 5. Comparison of inoculated and control seedlings of 19Y142, Akgün 12, and TEG 502.

may not appear more resistant compared to TEG 502. However, regarding the germination of control seeds, it should be considered that Akgün 12 has a $74.0 \%$ germination rate and TEG 502 has a $98.0 \%$ germination rate.

It has been thought that differences in resistance levels changed over time and the result obtained in the $4^{\text {th }}$ week gave a more accurate result. According to observation, pre-damping off refers to the percentage of seeds that die before germination, while post-damping off refers to the percentage of seedlings that die after germination. The rate of dead seeds before germination were significantly higher than the rate of dead seedlings after germination.

\section{Conclusion}

These 13 onion genotypes have never been used in a disease study. The results of Akgün 12 used in this study were like to previous studies. Accordingly, one can have an idea about the resistance level of 13 other onion genotypes grown under the same conditions as Akgün 12. However, the result of the Texas Early Grano 502 variety used in the study was not compatible with previous studies (Özer, 1998; Ko et al., 2002; Özer et al., 2004; Galvan et al., 2008; Nasr-Esfahani et al., 2013).

When the obtained results were analyzed, according to the survival percentages at the end of the $4^{\text {th }}$ week, it is possible to specify the resistance levels of onion genotypes as follows: Texas Early Grano 502, 19Y07, 19Y142, 19Y16, 19Y01, 19Y17, Akgün 12, 19Y18, 19Y34, 19Y46, 19Y19, 19Y06, 19Y73, 19Y15 and 19Y51. Since it was observed that the pre-damping-off severity was higher than the post-damping-off severity, the production of onion at the seed stage should be done more carefully and controlled. Since the aggressiveness of pathogens changes from region to region and onion varieties found as resistant will not always show the same performance in time.

\section{Acknowledgement}

This work is a part of Master Thesis and The Scientific and Technological Research Council of Turkey (TUBITAK) $117 \mathrm{G} 002$ project titled as "Development of Line and/or Variety in Winter Vegetable Cultivation". Special thanks go to TUBITAK for providing me partial scholarship during my master's degree program.

\section{References}

Abawi, G.S., \& Lorbeer, J.W. (1972). Several aspects of the ecology and pathology of Fusarium oxysporum $\mathrm{f}$. sp. cepae. Phytopathology, 62:870-876.

Bayraktar, H., \& Dolar, F.S. (2011). Molecular identification and genetic diversity of Fusarium species associated with onion fields in Turkey. Journal of Phytopathology, 159:28-34.

Behrani, G.Q., Syed, R.N., Abro, M.A., Jiskani, M.M., \& Khanzada, M.A. (2015). Pathogenicity and chemical control of basal rot of onion caused by Fusarium oxysporum f. sp. cepae. Pakistan Journal of Agriculture, Agricultural Engineering and Veterinary Sciences, 31:60-70.

Brayford, D. (1996). IMI Descriptions of Fungi and Bacteria, Set No. 127, Nos. 1261-1270.

Cramer, C.S. (2000). Breeding and genetics of Fusarium basal rot resistance in onion. Euphytica, 115:159-66.

Dissanayake, M.L.M.C., Kashıma, R., Tanaka, S., \& Ito, S.I. (2009). Genetic diversity and pathogenicity of Fusarium oxysporum isolated from wilted Welsh onion in Japan. Journal of General Plant Pathology, 75:125130.

Fantino, M.G., \& Schiavi, M. (1987). Onion breeding for tolerance to Fusarium oxysporum f. sp. cepae in Italy. Phytopathology Mediterranea, 26:108-112.

Galván, G.A., Koning-Boucoiran, C.F.S., Koopman W.J.M., Burger-Meijer K., González P.H., Waalwijk C., Kik C., \& Scholten O.E. (2008). Genetic variation among fusarium isolates from onion and resistance to fusarium basal rot in related allium species. European Journal of Plant Pathology, 121:499-512.

Ghanbarzadeh, B., Goltapeh, E.M., \& Safaie, N. (2014). Identification of Fusarium species causing basal rot of onion in East Azarbaijan province, Iran and evaluation of their virulence on onion bulbs and seedlings. Archives of Phytopathology and Plant Protection, 47:1050-1062.

Ko, S.S., Chang, W.N., Wang J.F., Cherng, S.J., \& Shanmugasundaram, S. (2002). Storage variability 
among short-day onion cultivars under high temperature and high relative humidity, and its relationship with disease incidence and bulb characteristics. Journal of American Society for Horticultural Science, 127:847-854.

Köycü, N.D., \& Özer, N. (1997). Determination of seedborne fungi in onion and their transmission to onion sets. Phytoparasitica, 25:25-31.

Lager, S. (2011). Survey of Fusarium species on yellow onion (Allium cepa) on Öland. MSc Thesis, Swedish University, Sweden.

Nasr Esfahani, M., Hossaini, M., \& Ashrafi, N. (2012). Screening of Iranian onion seed sets genotypes for resistance to Fusarium oxysporum f. sp. cepae. International Journal of Farming and Allied Sciences, 1:9-15.

Nasr Esfahani, M., Hosseini, M., Nasehi, A., \& Golkhandan, E. (2013). Screening of onion seed sets for resistance against new Iranian isolates of Fusarium oxysporum f. sp. cepae. Archives of Phytopathology and Plant Protection, 46:1864-1873.

Nasr Esfahani, M. (2018). Genetic and virulence variation in Fusarium oxysporum f. sp. cepae causing root and basal rot of common onion in Iran. Journal of Phytopathology, 166:572-580.

Özer, N. (1998). Reaction of some onion cultivars to Aspergillus niger V. Tiegh. and Fusarium oxysporum Schlecht. Journal of Turkish Phytopatholugy, 27:1726.

Özer, N., Köycü, D., Chilosi, G., Pizzuolo, P.H., Coşkuntuna, A., \& Magro, P. (2003). Pectolytic isoenzymes by Fusarium oxysporum f. sp. cepae and antifungal compounds in onion cultivars as a response to pathogen infection. Canadian Journal of Plant Pathology, 25:249-57.

Özer, N., Köycü, N.D., Chilosi, G., \& Magro, P. (2004). Resistance to fusarium basal rot of onion in greenhouse and field and associated expression of antifungal compounds. Phytoparasitica, 32:388-394.

Saxena, A., \& Cramer, C.S. (2009). Screening of onion seedlings for resistance against New Mexico isolates of Fusarium oxysporum f. sp. cepae. Journal of Plant Pathology, 91:199-202.

Singh, D., Dhillon, T.S., Singh, R., \& Kumar, R. (2018). Present status and future opportunities in onion research: A review. International Journal of Chemical Studies, 6:656-665.

Stadnik, M.J., \& Dhingra, O.D. (1997). Root infection by Fusarium oxysporum f. sp. cepae at different growth stages and its relation to the development of onion basal rot. Phytopathologia Mediterranea, 36:8-11.

Taylor, A., Vagany, V., Barbara, D.J., Thomas, B., Pink, D., Jones, J.E., \& Clarkson, J.P. (2013). Identification of differential resistance to six Fusarium oxysporum $\mathrm{f}$. sp. cepae isolates in commercial onion cultivars through the development of a rapid seedling assay. Plant Pathology, 62:103-11.

Türkkan, M., \& Karaca, G. (2006). Determination of fungal root rot disease agents associated with onion fields in Amasya province. Journal of Agricultural Sciences, 12:357-363.

Ünsal, İ., Kaş, S., \& Türkkan, M. (2019). Effect of some calcium salts on the growth and development of Fusarium oxysporum f. sp. cepae, the causal agent of Fusarium basal rot of onion. Akademik Ziraat Dergisi, 8:35-42. 